\title{
Bilateral Basal Ganglia Infarction and Bilateral Thalamic Lesions in Sudanese Pediatric Patient with COVID-19 and Malaria Co-Infection, a Case Report
}

Yassin Abdelrahim, Abdalla ${ }^{1}$, Mohannad Abdalfdeel Almahie Shaban² ${ }^{2}$ Khabab Mohamed Ahmed $^{3}$, Mazin S. Hassan Haroun ${ }^{3}$, Moh. Eljack ${ }^{4}$, Khalid Sidahmed Eltom ${ }^{5}$, and Rasha Sidahmed Elhassan ${ }^{5}$

${ }^{1}$ Omdurman Islamic University Faculty of Medicine and Health Sciences

${ }^{2}$ Alzaiem Alazhari University Faculty of Medicine

${ }^{3}$ University of Khartoum Faculty of Medicine

${ }^{4}$ Medani Heart Centre

${ }^{5}$ Alribat Teaching Hospital

December 23, 2021

\begin{abstract}
COVID-19 is of uncommon diagnosis in pediatric with their presentation in much of time of a nonspecific entity; here we experienced a case of two years old female with Malaria presented with fever, cough, rhinorrhea, hemoptysis and convulsion diagnosed as COVID-19, complicated with encephalitis, received treatment and improved over weeks.
\end{abstract}

\section{Hosted file}

pediatric case reports.docx available at https://authorea.com/users/452467/articles/550533bilateral-basal-ganglia-infarction-and-bilateral-thalamic-lesions-in-sudanese-pediatricpatient-with-covid-19-and-malaria-co-infection-a-case-report

\section{Hosted file}

Pediatric Supporting Files.docx available at https://authorea.com/users/452467/articles/ 550533-bilateral-basal-ganglia-infarction-and-bilateral-thalamic-lesions-in-sudanesepediatric-patient-with-covid-19-and-malaria-co-infection-a-case-report 